\title{
ANXA3 is upregulated by hypoxia-inducible factor 1-alpha and promotes colon cancer growth
}

\author{
Kunli Du${ }^{1}$, Jiahui Ren ${ }^{2}$, Zhongxue $\mathrm{Fu}^{3}$, Xingye $\mathrm{Wu}^{3}$, Jianyong Zheng ${ }^{1}, \mathrm{Xing}^{\mathrm{Li}}{ }^{4}$ \\ ${ }^{1}$ Department of Gastrointestinal Surgery, The First Affiliated Hospital of Air Force Medical University, Xi'an, China; ${ }^{2}$ Department of Anus and \\ Intestine Surgery, Xi'an Mayinglong Anorectal Hospital, Xi'an, China; ${ }^{3}$ Department of Gastrointestinal Surgery, The First Affiliated Hospital of \\ Chongqing Medical University, Chongqing, China; ${ }^{4}$ Nanjing Yuheming Medical Nutrition Research Institute, Nanjing, China \\ Contributions: (I) Conception and design: J Zheng; (II) Administrative support: X Li; (III) Provision of study materials or patients: K Du, J Ren, Z \\ Fu; (IV) Collection and assembly of data: K Du, J Ren, Z Fu; (V) Data analysis and interpretation: X Wu; (VI) Manuscript writing: All authors; (VII) \\ Final approval of manuscript: All authors. \\ Correspondence to: Xingye Wu. Department of Gastrointestinal Surgery, The First Affiliated Hospital of Chongqing Medical University, Youyi \\ Road 1st, Yuzhong District, Chongqing 400016, China. Email: wuxingye0221@163.com; Jianyong Zheng. Department of Gastrointestinal \\ Surgery, The First Affiliated Hospital of Air Force Medical University, 127 Changle West Road, Xincheng District, Xi'an 710000 , China. \\ Email: drzhang139@gmail.com.
}

\begin{abstract}
Background: Annexin A3 (ANXA3) is overexpressed in various cancers and is a potential target for cancer treatment. However, clinical implication and biological function of ANXA3 in colon cancer remain unknown. This study aimed to investigate the relationship between hypoxia-inducible factor 1-alpha (HIF-1 $\alpha)$ and ANXA3, and explore the function of ANXA3 in colon carcinoma.

Methods: Expression levels of HIF-1 $\alpha$ and ANXA3 in human colon carcinoma specimens and colon cancer cell lines were detected by immunohistochemistry, real-time PCR and Western blot analysis. The proliferation of colon cancer cells was examined. Nude mice were used for xenograft tumor model, and HIF$1 \alpha$ siRNA or control adenovirus was injected into the tumor.

Results: HIF-1 $\alpha$ and ANXA3 expression levels were higher in colon cancer tissues than their expression levels in normal colon tissues. In addition, HIF-1 $\alpha$ and ANXA3 expression increased in colon cancer cells under hypoxic condition. Knockdown of HIF-1 $\alpha$ decreased HIF-1 $\alpha$ and ANXA3 expression, and inhibited the proliferation and growth of colon cancer cells. In nude mouse model, silencing HIF-1 $\alpha$ decreased volume of xenograft tumor and ANXA3 expression.
\end{abstract}

Conclusions: ANXA3 expression is upregulated by HIF-1 $\alpha$ in colon cancer in response to hypoxic stress and contributes to colon tumor growth. ANXA3 may represent a new therapeutic target for colon carcinoma.

Keywords: Hypoxia-inducible factor 1-alpha (HIF-1 $\alpha$ ); annexin A3 (ANXA3); colon cancer; hypoxia

Submitted Feb 12, 2020. Accepted for publication Sep 30, 2020.

doi: $10.21037 /$ tcr-20-994

View this article at: http://dx.doi.org/10.21037/tcr-20-994

\section{Introduction}

Colon cancer is one of the most prevalent gastrointestinal tumors in the world. Although conventional treatments of colon cancer, such as surgery, radiotherapy and chemotherapy have improved, the rate of mortality and recurrence remain at a high level. The development and progression of colon cancer is driven by abnormal expression of oncogenes and tumor suppressors (1). Therefore, it is important to explore new targets to develop therapeutic strategies of colon cancer.

Hypoxia is an important factor of microenvironment of most solid tumors (2). Hypoxia-inducible factor 1 (HIF1 ) is a heterodimeric transcription factor consisted of HIF$1 \alpha$ subunit and HIF-1 $\beta$ subunit (3). HIF-1 $\beta$ subunit is constitutively expressed, but HIF-1 $\alpha$ subunit is regulated 
by oxygen which is stable under hypoxic condition but is rapidly degraded under normoxic conditions (3). HIF-1 $\alpha$ is an essential factor to regulate transcriptional response of tumor under hypoxic environment, and has been reported to play important role in the development and progression of many tumors (3-5).

Annexins are a class of calcium-dependent phospholipidbinding proteins and include five families $\mathrm{A}$ to $\mathrm{E}$ (6). Annexin A3 (ANXA3) is one member of annexin A family, and the function of ANXA3 in tumors is under debate. One study reported that ANXA3 was overexpressed in colorectal tumor tissues based on immunoblotting and tissue microarray analysis (6). In addition, overexpression of ANXA3 has been reported in hepatocellular carcinoma and ANXA3 may promote HCC progression and chemoresistance (7). However, another study showed that low ANXA3 expression was associated with tumor progression in papillary thyroid cancer (8). Our previous study indicated that HIF-1 $\alpha$ had a significant correlation with ANXA2 in colon cancer (9). However, the role of ANXA3 in colon cancer remains unclear.

Therefore, in this study we aimed to employ both in vitro and in vivo approaches to evaluate whether HIF-1 $\alpha$ could regulate ANXA3 in colon cancer cells, and investigate their role in colon tumor. We present the following article in accordance with the ARRIVE reporting checklist (available at http://dx. doi. org/10. 21037/tcr-20-994).

\section{Methods}

\section{Human tissue samples}

Colon cancer tissue and corresponding normal tissue were collected from 60 patients diagnosed with colon adenocarcinoma from December 2013 to June 2014 who underwent radical colectomy without preoperative chemoradio-therapy at Department of Gastrointestinal Surgery of The First Affiliated Hospital of Chongqing Medical University. The histologic types of the specimens were independently determined by two pathologists. All the patients' clinical parameters including age, gender, TNM stage (UICC), histological stage and lymph node status were collected. The study was conducted in accordance with the Declaration of Helsinki (as revised in 2013). This study was approved by the Ethics Committee of The First Affiliated Hospital of Chongqing Medical University (Chongqing, China) (Approval No. 20150612). All patients provided written informed consent.

\section{Cell culture and virus infection}

Human colon cancer cells (SW480, SW620, HCT116 and HT29) were purchased from the Shanghai Cell Bank at the Chinese Academy of Sciences (Shanghai, China), and cultured in RPMI 1640 medium supplemented with $10 \%$ fetal calf serum (Hyclone, Shanghai, China) and 1\% penicillin/streptomycin (Beyotime, Jiangsu, China) at $37^{\circ} \mathrm{C}$ in a humidified incubator with $5 \% \mathrm{CO}_{2}$ and $21 \% \mathrm{O}_{2}$ atmosphere (normoxic conditions). For hypoxic treatment, cells were incubated with $1 \% \mathrm{O}_{2}$ in a three-chamber air incubator as described previously (10). Recombinant adenovirus harboring siRNA to HIF-1 $\alpha$ (NM_001530) or scramble siRNA control were purchased from Hanheng Biotech (Shanghai, China). The sequence of siRNA to HIF$1 \alpha$ was as follow: 5 '-GGAAATGAGAGAAATGCTTAC-3'. SW480 and SW620 cells $\left(5 \times 10^{5} / \mathrm{mL}\right)$ in logarithmic phase were seeded in 6-well plate, and then infected with adenovirus vector. Fluorescence microscopy was used to observe fluorescence $24 \mathrm{~h}$ after infection. Infection efficiency was determined by the percent of cells expressing green fluorescence protein (GFP).

\section{Immunobistochemistry}

Immunohistochemical staining was performed using Immunohistochemical SP9000 kit (Zhongshan Golden Bridge, Beijing, China) according the manufacturer's instructions. Briefly, $4 \mu \mathrm{m}$ sections were cut from formaldehyde fixed and paraffin wax embedded tumor tissues. Endogenous peroxidase activity was blocked by $3 \% \mathrm{H}_{2} \mathrm{O}_{2}$ for $10 \mathrm{~min}$, the slides were microwaved in citrate buffer for $15 \mathrm{~min}$ for antigen retrieval, and then blocked in $5 \%$ bovine serum albumin (BSA) for $30 \mathrm{~min}$ at room temperature. The slides were then incubated with HIF$1 \alpha$ and ANXA3 polyclonal antibodies (GTX 127309, GTX103330, Gene Tex, USA, 1:200) overnight at $4{ }^{\circ} \mathrm{C}$. The slides were incubated with biotinylated secondary goat anti-rabbit antibody and avidin-biotin-peroxidase complex for $20 \mathrm{~min}$ at room temperature, followed by incubation with 3,3-diaminobenzidine (DAB). Finally, the slides were counter-stained with hematoxylin.

\section{Real-time PCR}

Total RNAs from cells and tissues were isolated using TRIzol as described previously (11). cDNA was synthesized using RT kit (TaKaRa, Dalian, China). Real-time PCR was 
performed on CFX96 ${ }^{\mathrm{TM}}$ Real-Time System (Bio-Rad, USA) using SYBR Premix Ex Taq ${ }^{\mathrm{TM}} \mathrm{II}$ (TaKaRa, Dalian, China). The primers of HIF- $1 \alpha$ and ANXA3 were as follow: HIF$1 \alpha$ forward: 5'-CCACAGAAACTACCTTCAACTCC-3' and reverse: 5'-GTGATCTCCTTCTGCATCCTGT-3'. ANXA3 forward: 5'-CAGGACAAG CAGGCAAATGAA-3' and reverse: 5'-TCTGCCATCTGCCAAAGTCAA-3'. $\beta$-actin was used as an internal control. The relative expression levels of mRNAs were calculated using $2^{-(\Delta \mathrm{Ct} \text { sample }}$ $-\Delta$ Ct control) method.

\section{Western blot analysis}

Total proteins were extracted by RIPA lysis buffer (Beyontime, Jiangsu, China). The protein concentration was detected by BCA Protein Assay kit (Pierce, USA) according to the manufacturer's instructions. The proteins were separated by $10 \%$ SDS-PAGE and transferred onto PVDF membranes (Millipore, Guangzhou, China). Next, the membranes were blocked in $5 \%$ non-fat dry milk for 1 h. Then the membranes were probed by antibody for HIF$1 \alpha(1: 1,000)$, ANXA3 $(1: 800)$ or $\beta$-actin $(1: 500$, Boster, Biotechnology, Wuhan, China) overnight at $4{ }^{\circ} \mathrm{C}$. Antibodyreactive bands were detected using chemiluminescence detection reagents on a Fushion image system.

\section{Cell proliferation assay}

Cell proliferation was measured using CCK8 reagent as described previously (12). Briefly, cells in the logarithmic growth phase were seeded in 96 -well plates at $2 \times 10^{3}$ cells/ well. After culture for $24 \mathrm{~h}, 10 \mu \mathrm{L}$ of CCK8 was add to each well, and the cells were incubated at $37^{\circ} \mathrm{C}$ for $2 \mathrm{~h}$. Finally, the absorbance was measured at $450 \mathrm{~nm}$ using microplate reader (Thermo Multiskan spectrum 1500).

\section{Clone formation assay}

A total of 500 SW480 or SW620 cells were seeded in 24well plate maintained in RMPI 1640 supplemented with $10 \%$ fetal calf serum for 2 weeks. Colonies were fixed with $4 \%$ paraformaldehyde for $15 \mathrm{~min}$ and stained with $0.1 \%$ crystal violet.

\section{Animal study}

Five-week-old female BALB/C nude mice were purchased from the Laboratory Animal Center of Chongqing Medical
University, and kept in a specific pathogen-free unit under isothermal conditions. All experimental procedures were approved by Committee of Chongqing Medical University for Animal Care (No. 20150024) and Use in accordance with National Guide on Animal Care and Use. Total $5 \times 10^{6}$ cells were injected subcutaneously to the mice and the volume of tumor was measured every 3 days. When the volume reached $50-70 \mathrm{~mm}^{3}$, the mice were randomly divided into two groups (three mice in experimental group and three mice in control group) and HIF- $1 \alpha$ siRNA or control adenovirus was injected into the tumor every week for four times, respectively. Tumor volume in mice was measured. Finally, animals were sacrificed and the tumors were resected for immunohistochemical analysis.

\section{Statistical analysis}

All the statistical analyses were processed using statistical software SPSS 16.0 (SPSS, Inc., Chicago, IL, USA). Data were analyzed by student's $t$-test and chi-square test. The correlation between HIF- $1 \alpha$ and ANXA3 was evaluated using a Spearman's rank correlation. $\mathrm{P}<0.05$ was considered statistically significant.

\section{Results}

\section{HIF-1 $\alpha$ and AXNA3 are overexpressed in colon cancer tissues}

HIF $-1 \alpha$ and ANXA 3 proteins were expressed predominantly in colon cancer tissues but were faintly expressed in normal cancer tissues. HIF-1 $\alpha$ was mainly expressed in the cytoplasm and the nucleus of colon cancer cells and ANXA3 was mainly distributed in the membrane and cytoplasm (Figure 1). Forty-five (75\%) of 60 colon cancer cases were positive for HIF- $1 \alpha$ and 48 (80\%) of 60 colon cancer cases were positive for ANXA3. We observed a positive correlation between HIF- $1 \alpha$ and ANXA3 expression in 60 colon cancer tissues $(\mathrm{r}=0.48, \mathrm{P}=0.001)$ (Table 1). The relationship between HIF-1 $\alpha$ and ANXA3 expression, and clinicopathological features of patients is shown in Table 2. We found that the expression of HIF$1 \alpha$ and ANXA3 was associated with tumor size, lymphatic metastasis and clinic staging of colon cancer, but not with other clinicopathological features including patient gender and age.

qRT-PCR analysis showed that HIF- $1 \alpha$ and ANXA3 mRNA levels were significantly increased in colon cancer 


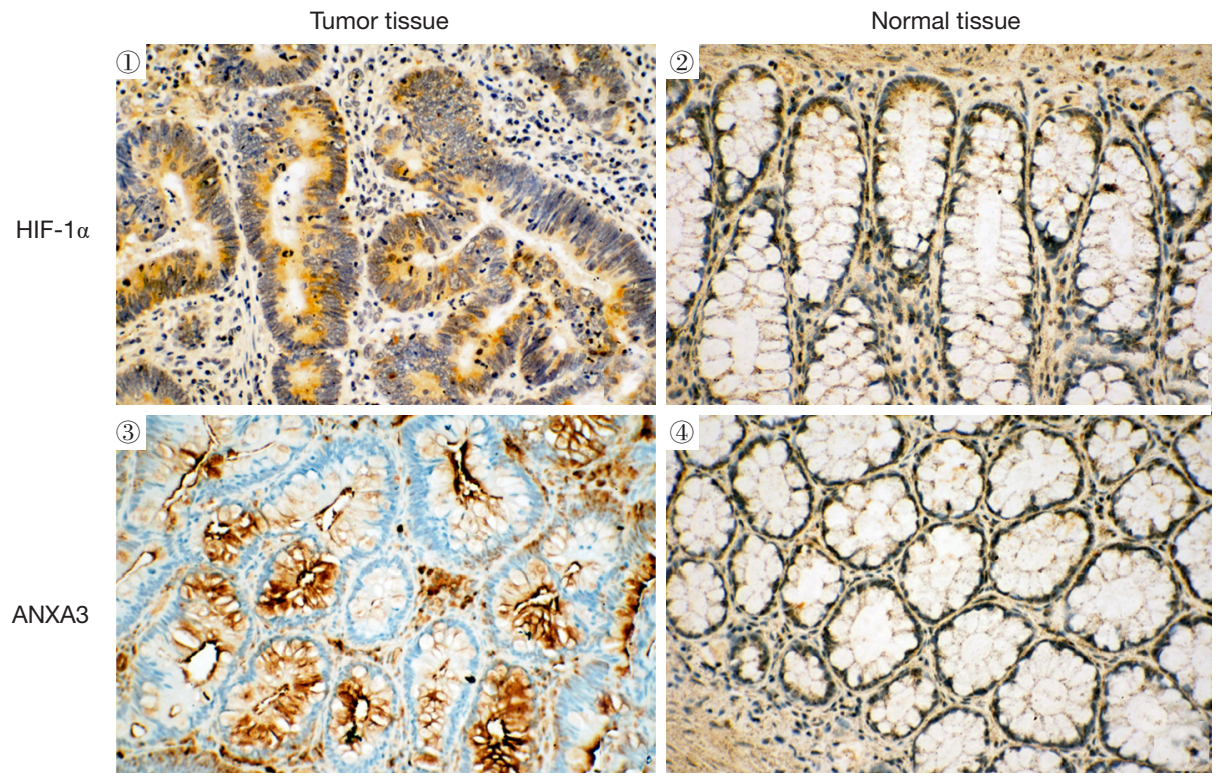

Figure 1 Immunohistochemical staining of HIF-1 $\alpha$ and ANXA3 in colon cancer and normal colon tissues. Positive expression was visualized by brown staining. Original magnification, $\times 200$. HIF-1 $\alpha$, hypoxia-inducible factor 1-alpha; ANXA3, annexin A3.

Table 1 Correlation of HIF-1 $\alpha$ and ANXA3 expression in colon cancer tissue samples

\begin{tabular}{lccc}
\hline \multirow{2}{*}{$\begin{array}{l}\text { Expression of } \\
\text { ANXA3 }\end{array}$} & \multicolumn{2}{c}{ Expression of HIF-1 $\alpha$} & \multirow{2}{*}{ P value } \\
\cline { 2 - 3 } & Positive $(n=45)$ & Negative $(n=15)$ & \\
\cline { 1 - 2 } Positive $(n=48)$ & 41 & 7 & \\
Negative $(n=12)$ & 4 & 8 & \\
\hline
\end{tabular}

HIF-1 $\alpha$, hypoxia-inducible factor 1-alpha; ANXA3, annexin A3.

tissues compared with corresponding normal colon tissues $(\mathrm{P}<0.01$, Figure $2 A)$. Moreover, Western blotting demonstrated higher expression of HIF-1 $\alpha$ and ANXA3 in colon cancer tissues than in normal colon tissues $(\mathrm{P}<0.01$, Figure 2B).

\section{HIF-1a regulates ANXA3 expression in colon cancer cells}

The expression of HIF- $1 \alpha$ and ANXA3 protein levels were measured by Western blot in four colon cancer cells including SW480, SW620, HCT116 and HT29. We found that protein levels of HIF- $1 \alpha$ and ANXA3 were significantly higher in SW480 and SW620 cells than in HCT116 and HT29 cells (Figure 3). Thus, we chose SW480 and SW620 cells for subsequent studies. Cells were exposed to hypoxia condition for $24 \mathrm{~h}$, and the expression of HIF-1 $\alpha$ and
ANXA3 significantly increased under hypoxic condition $(\mathrm{P}<0.01$, Figure $4 A)$, but their expression decreased in cells treated with HIF-1 $\alpha$ siRNA under hypoxic condition $(\mathrm{P}<0.01$, Figure $4 B)$. These findings indicated that HIF-1 $\alpha$ may regulate ANXA3 expression in colon cancer cells.

\section{HIF-1a knockdown inhibited colon cancer cell proliferation}

To evaluate the role of HIF- $1 \alpha$ in proliferation ability of colon cancer cells, SW480 and SW620 cells were transfected with HIF-1 $\alpha$ siRNA. As shown in Figure $5 A$, the proliferation of colon cancer cells decreased after transfection with HIF-1 $\alpha$ siRNA compared to control group $(\mathrm{P}<0.05)$. Furthermore, clone formation assay showed decreased growth of both SW480 and SW620 cells after transfection with HIF- $1 \alpha$ siRNA $(\mathrm{P}<0.05$, Figure 5B).

\section{HIF-1a knockdown inbibited colon cancer growth in vivo}

To explore the effects of HIF-1 $\alpha$ on ANXA3 expression and colon cancer growth in vivo, SW480 and SW620 cells were used to establish xenograft tumor model. As shown in Figure 6A, tumor volume of HIF- $1 \alpha$ siRNA group was much smaller than that of flank control group $(n=3)$. Furthermore, immunohistochemistry analysis showed 
Table 2 Correlation of HIF- $1 \alpha$ and ANXA3 expression and clinic parameters

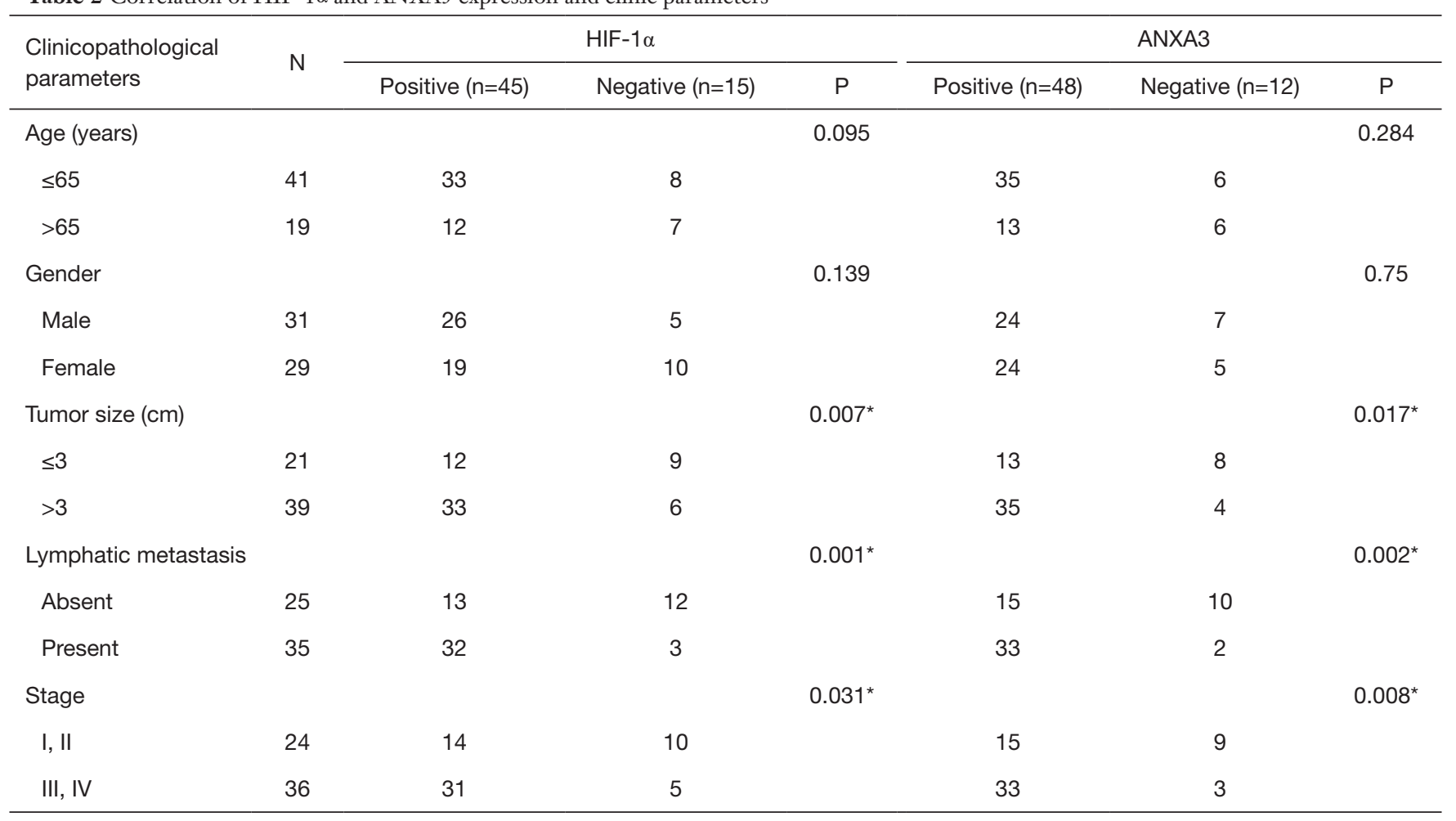

${ }^{*}, \mathrm{P}<0.05$. HIF-1 $\alpha$, hypoxia-inducible factor 1-alpha; ANXA3, annexin A3.

that the expression of HIF- $1 \alpha$ and ANXA3 significantly decreased in HIF-1 $\alpha$ siRNA group compared with control group (Figure 6B).

\section{Discussion}

In present study, HIF-1 $\alpha$ and ANXA3 expression was detected in 60 colon cancer tissues by immunohistochemistry, Western blot and qRT-PCR. The results showed that the expression of HIF- $1 \alpha$ and ANXA3 in colon cancer tissues was significantly higher than in control tissues and was associated with tumor size, lymphatic metastasis and clinic staging. In addition, Spearman's rank correlation analysis demonstrated a significant positive correlation between HIF-1 $\alpha$ expression and ANXA3 expression. In vitro, we found that the expression of ANXA3 was upregulated in SW480 and SW620 cells exposed to hypoxic condition and downregulated in cells transfected with HIF- $1 \alpha$ siRNA. In addition, HIF- $1 \alpha$ siRNA could reduce proliferation ability in both cell lines. In vivo, we demonstrated that the volume of tumors were decreased in HIF- $1 \alpha$ siRNA groups compared with control groups. The expression of ANXA3 was markedly inhibited by HIF-1 $\alpha$ siRNA in xenograft tumor model.

Annexins participate in several processes including cancer cell proliferation, apoptosis and invasion (13-15). ANXA3 is a member of annexin family (16). Accumulating evidences suggest that the function of ANXA3 could be an oncogene or tumor suppressors in different kinds of cancer. High expression of ANXA3 was found in tumors such as lung cancer, gastric cancer and colorectal cancer (17-19). However, low expression of ANXA3 was found in prostate cancer, papillary thyroid cancer and follicular thyroid cancer $(20,21)$. Zeng et al. found that ANXA3 was an independent prognostic factor and regulated breast cancer cell apoptosis through modulating Bcl-2/Bax balance (22). Elevated expression of ANXA3 could increase platinum resistance in ovarian cancer (23). In addition, ANXA3 was overexpressed in HCC and promoted HCC progression and chemoresistance, and played a role in HCC CSCs maintenance (24). Up to now, the role of ANXA3 in colon cancer remains unclear. In this study we found that hypoxiainduced ANXA3 expression was HIF- $1 \alpha$ dependent, because HIF-1 $\alpha$ siRNA inhibited overexpression of ANXA3 induced 
A

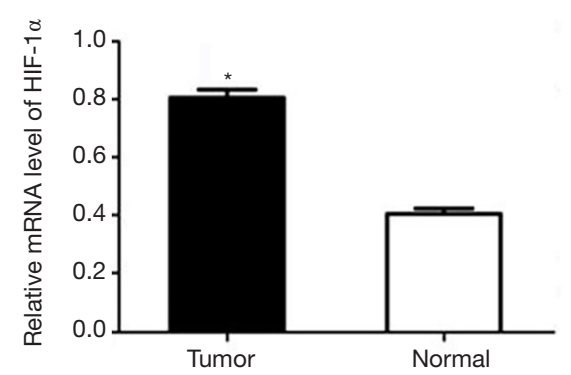

B

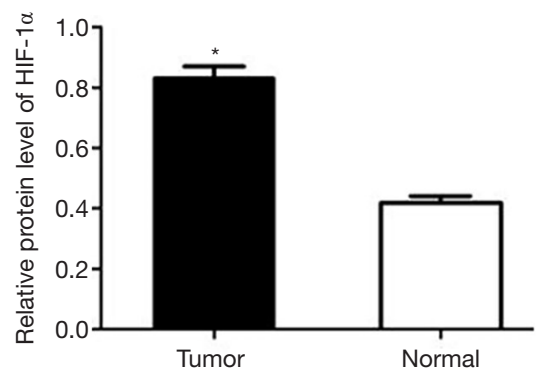

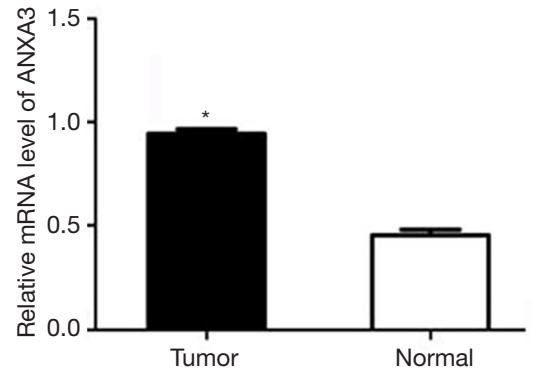

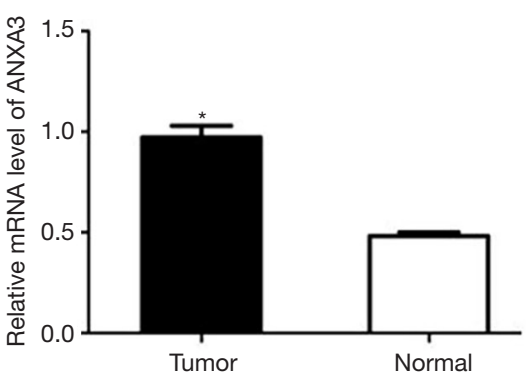

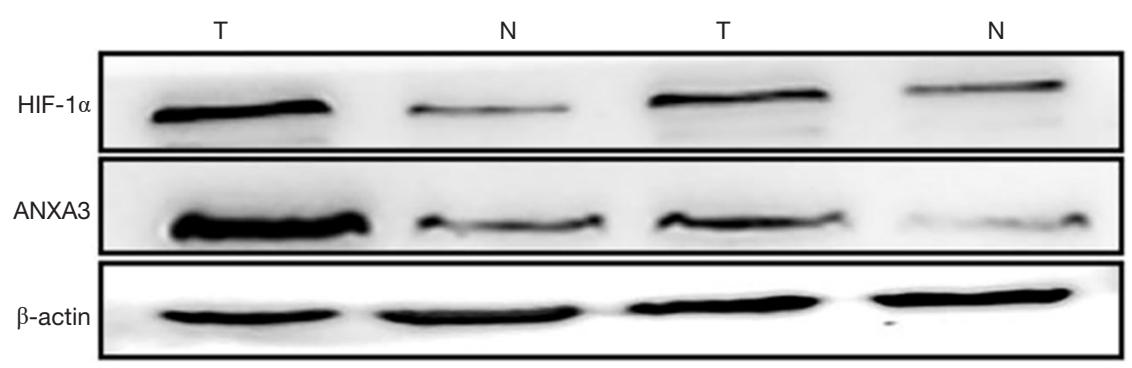

Figure 2 Detection of HIF- $1 \alpha$ and ANXA3 expression in colon cancer and normal colon tissues. (A) qRT-PCR analysis of HIF-1 $\alpha$ and ANXA3 mRNA levels in colon cancer $(n=60)$ and normal colon tissues $(n=60)$. (B) Western blot analysis of HIF-1 $\alpha$ and ANXA3 protein levels in tumor $(\mathrm{T})$ and normal $(\mathrm{N})$ tissues. The average signal intensity was standardized to $\beta$-actin. Data was analyzed using Student's $t$-test and was shown as means \pm SD of triplicate experiments. *, $\mathrm{P}<0.05$. HIF-1 $\alpha$, hypoxia-inducible factor 1-alpha; ANXA3, annexin A3.

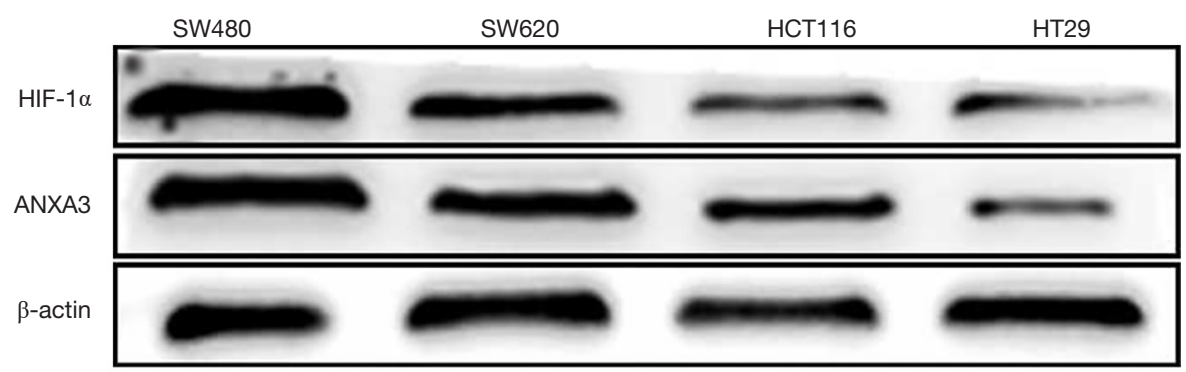

Figure 3 Detection of HIF-1 $\alpha$ and ANXA3 protein levels in SW480, SW620, HCT116 and HT29 colon cancer cells under normoxic condition. HIF-1 $\alpha$, hypoxia-inducible factor 1-alpha; ANXA3, annexin A3. 
A

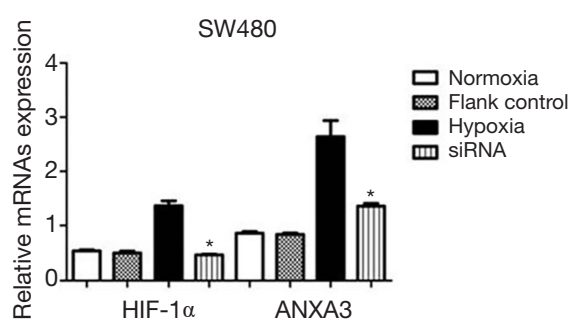

B

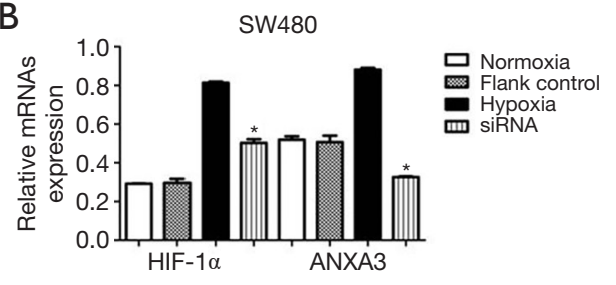

SW480

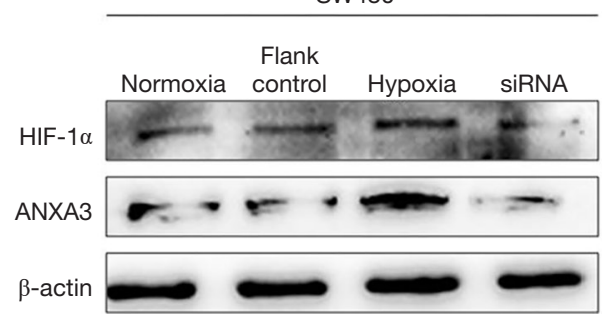

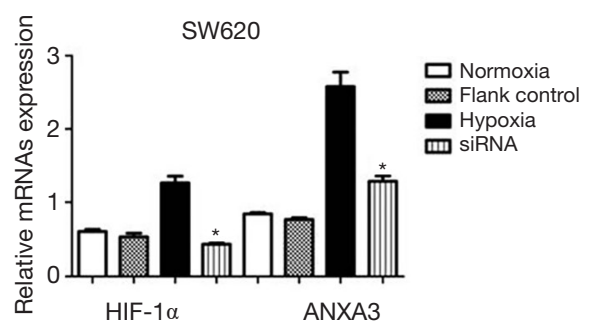

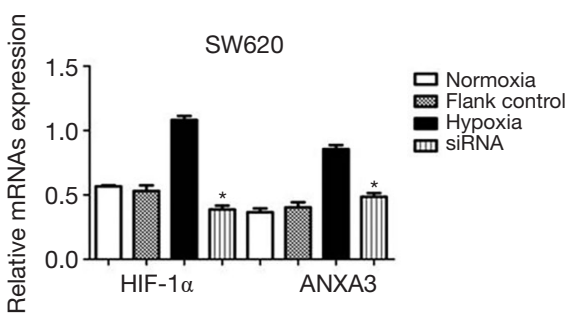

SW620

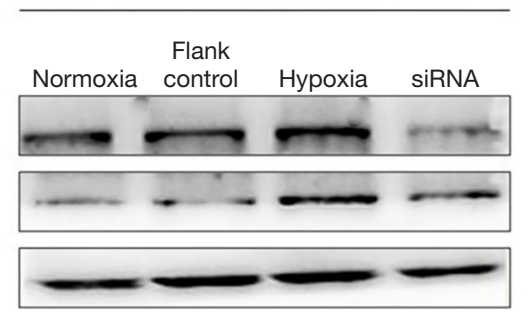

Figure 4 HIF-1 $\alpha$ regulates ANXA3 expression in SW480 and SW620 cells. The expression of HIF-1 $\alpha$ and ANXA3 was measured by qRTPCR and Western blot. (A) mRNA levels of HIF-1 $\alpha$ and ANXA3 were significantly increased in hypoxia group and decreased in HIF-1 $\alpha$ siRNA group. (B) Protein levels of HIF-1 $\alpha$ and ANXA3 were significantly increased in hypoxia group and suppressed in HIF-1 $\alpha$ siRNA group under hypoxic stress. The flank control has no effect on the expression of HIF-1 $\alpha$ and ANXA3. * P $<0.05$. HIF-1 $\alpha$, hypoxia-inducible factor 1-alpha; ANXA3, annexin A3.

by hypoxic condition in colon cancer cells. Angiogenesis is a key process in tumor progression by providing adequate blood supply for growing tumors (25). Therefore, ANXA3 may promote tumor growth in colon cancer through angiogenesis.

In addition, our study demonstrated that HIF- $1 \alpha$ siRNA treated colon cancer cells had reduced ability to form tumors in a nude mouse xenograft mode. The mean tumor volume of siRNA group was smaller than that of flank control group. Moreover, the expression of HIF$1 \alpha$ and ANXA3 was inhibited by HIF- $1 \alpha$ siRNA in tumor xenograft tumor tissues. These results reveal that HIF$1 \alpha$ could affect the expression of ANXA3 in vivo, which further supports that ANXA3 and HIF-1 $\alpha$ work together to promote colon tumor. However, our study has limitations because we did not explore the detailed mechanism by which HIF- $1 \alpha$ regulate the expression of ANXA3 in colon cancer cells. Furthermore, our sample size of colon cancer tissues is relatively small. More clinical samples are needed to confirm the significance of ANXA3 in colon cancer patients, especially the association of ANXA3 with their prognosis.

In conclusion, our study provides evidence that ANXA3 is overexpressed in colon cancer. Furthermore, we reveal that ANXA3 expression is upregulated by HIF- $1 \alpha$ in colon cancer in response to hypoxic stress and contributes to colon tumor growth. ANXA3 may represent a new therapeutic target for colon carcinoma. 
A
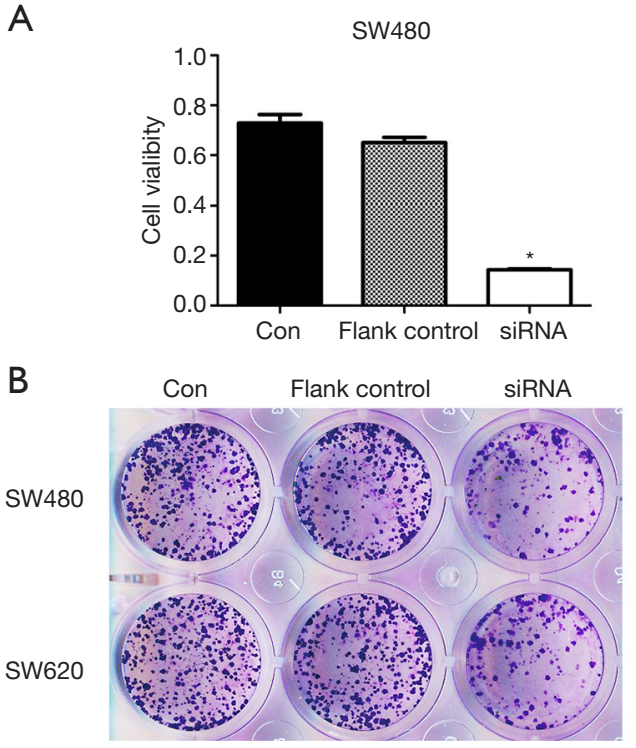

Figure 5 HIF-1 $\alpha$ knockdown inhibits the proliferation of colon cancer cells. (A) CCK8 assay. (B) Clone formation assay (crystal violet staining). *, $\mathrm{P}<0.05$. HIF-1 $\alpha$, hypoxia-inducible factor 1-alpha.

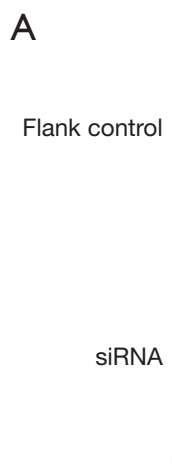

B

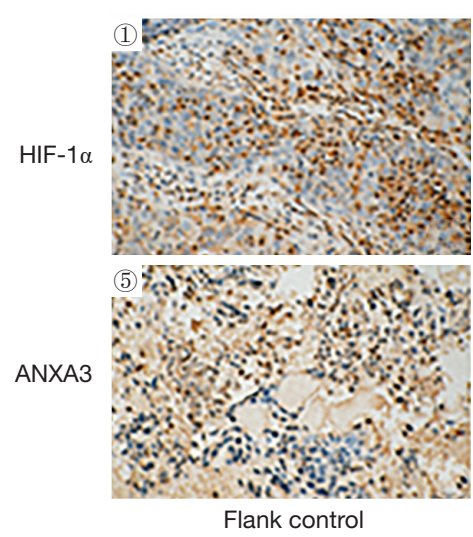

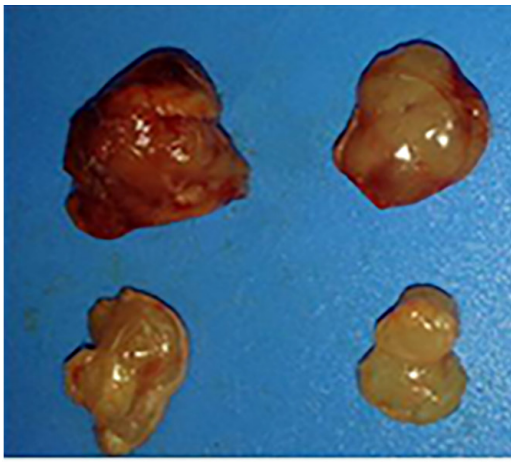

SW480

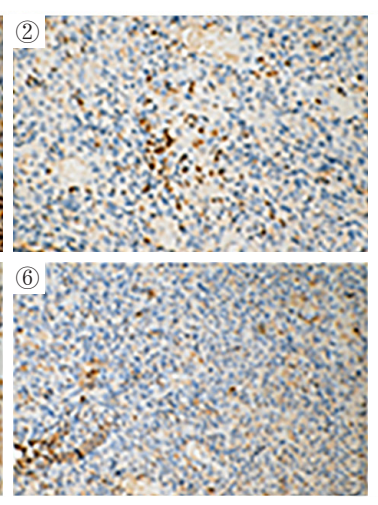

SiRNA
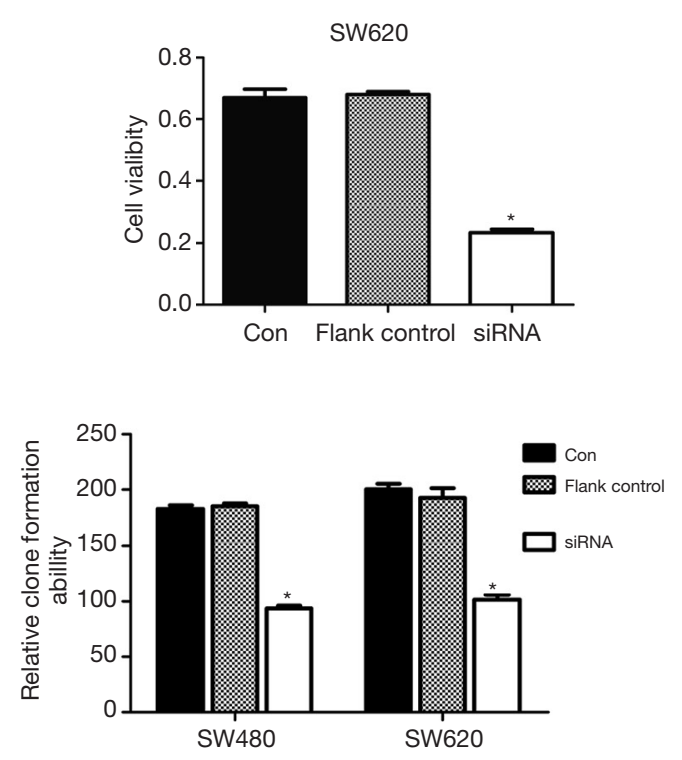


\section{Acknowledgments}

The authors gratefully thank the Central Laboratory of The First Affiliated Hospital of Chongqing Medical University for providing equipment support.

Funding: This work was supported by a National Natural Science Foundation of China (No. 81201916 and No. $81172295)$, and the funder has no role in study design.

\section{Footnote}

Reporting Checklist: The authors have completed the ARRIVE reporting checklist. Available at http://dx. doi. org/10. 21037/tcr-20-994

Data Sharing Statement: Available at http://dx. doi. org/10. 21037/tcr-20-994

Conflicts of Interest: All authors have completed the ICMJE uniform disclosure form (available at http://dx. doi. org/10. 21037/tcr-20-994). The authors have no conflicts of interest to declare.

Ethical Statement: The authors are accountable for all aspects of the work in ensuring that questions related to the accuracy or integrity of any part of the work are appropriately investigated and resolved. The study was conducted in accordance with the Declaration of Helsinki (as revised in 2013). The study was approved by Ethics Committee of The First Affiliated Hospital of Chongqing Medical University (Approval No. 20150612), and informed consent was taken from all the patients. All experimental procedures were approved by Committee of Chongqing Medical University for Animal Care (No. 20150024) and Use in accordance with National Guide on Animal Care and Use.

Open Access Statement: This is an Open Access article distributed in accordance with the Creative Commons Attribution-NonCommercial-NoDerivs 4.0 International License (CC BY-NC-ND 4.0), which permits the noncommercial replication and distribution of the article with the strict proviso that no changes or edits are made and the original work is properly cited (including links to both the formal publication through the relevant DOI and the license). See: https://creativecommons.org/licenses/by-nc-nd/4.0/.

\section{References}

1. Semlali A, Parine NR, Al-Numair NS, et al. Potential role of Toll-like receptor 2 expression and polymorphisms in colon cancer susceptibility in the Saudi Arabian population. Onco Targets Ther 2018;11:8127-41.

2. Fujikuni N, Yamamoto H, Tanabe K, et al. Hypoxiamediated CD24 expression is correlated with gastric cancer aggressiveness by promoting cell migration and invasion. Cancer Sci 2014;105:1411-20.

3. Wu XY, Fu ZX, Wang XH. Effect of hypoxia-inducible factor 1-alpha on Survivin in colorectal cancer. Mol Med Rep 2010;3:409-15.

4. Wan J, Chai H, Yu Z, et al. HIF-1 $\alpha$ effects on angiogenic potential in human small cell lung carcinoma. J Exp Clin Cancer Res 2011;30:77.

5. Gao H, Xie J, Peng J, et al. Hispidulin inhibits proliferation and enhances chemosensitivity of gallbladder cancer cells by targeting HIF-1 $\alpha$. Exp Cell Res 2015;332:236-46.

6. Madoz-Gúrpide J, López-Serra P, Martínez-Torrecuadrada JL, et al. Proteomics-based validation of genomic data: applications in colorectal cancer diagnosis. Mol Cell Proteomics 2006;5:1471-83.

7. Pan QZ, Pan K, Weng DS, et al. Annexin A3 promotes tumorigenesis and resistance to chemotherapy in hepatocellular carcinoma. Mol Carcinog 2015;54:598-607.

8. Jung EJ, Moon HG, Park ST, et al. Decreased annexin A3 expression correlates with tumor progression in papillary thyroid cancer. Proteomics Clin Appl 2010;4:528-37.

9. Wu XY, Fu ZX, Wang XH, et al. Identification of differential proteins in colon cancer SW480 cells with HIF1-alpha silence by proteome analysis. Neoplasma 2010;57:299-305.

10. Romain B, Hachet-Haas M, Rohr S, et al. Hypoxia differentially regulated CXCR4 and CXCR7 signaling in colon cancer. Mol Cancer 2014;13:58.

11. Zhong J, Deng L, Jiang Y, et al. Gene expression profiling of HepG2 cells after treatment with black tea polyphenols. Biocell 2018;42:99-104.

12. Zhang B, Zhang Y, Zhang X, et al. Suspension state promotes extravasation of breast tumor cells by increasing integrin $\beta 1$ expression. Biocell 2018;42:17-24.

13. Chaudhary P, Thamake SI, Shetty P, et al. Inhibition of triple-negative and Herceptin-resistant breast cancer cell proliferation and migration by Annexin A2 antibodies. Br J 
Cancer 2014;111:2328-41.

14. Bhardwaj A, Ganesan N, Tachibana K, et al. Annexin A1 preferentially predicts poor prognosis of basal-like breast cancer patients by activating mTOR-S6 signaling. PLoS One 2015;10:e0127678.

15. Liu QH, Shi ML, Bai J, et al. Identification of ANXA1 as a lymphatic metastasis and poor prognostic factor in pancreatic ductal adenocarcinoma. Asian Pac J Cancer Prev 2015;16:2719-24.

16. Gerke V, Moss SE. Annexins: from structure to function. Physiol Rev 2002;82:331-71.

17. Liu YF, Xiao ZQ, Li MX, et al. Quantitative proteome analysis reveals annexin A3 as a novel biomarker in lung adenocarcinoma. J Pathol 2009;217:54-64.

18. Zhai JM, Sun SJ, Wang W, et al. Expression of annexin A3 in gastric cancer and its correlation with proliferation and apoptosis. Asian Pac J Cancer Prev 2014; 15:3001-4.

19. Chang YT, Yao CT, Su SL, et al. Verification of gene expression profiles for colorectal cancer using 12 internet public microarray datasets. World J Gastroenterol 2014;20:17476-82.

Cite this article as: Du K, Ren J, Fu Z, Wu X, Zheng J, Li X. ANXA3 is upregulated by hypoxia-inducible factor 1-alpha and promotes colon cancer growth. Transl Cancer Res 2020;9(12):74407449. doi: 10.21037/tcr-20-994
20. Köllermann J, Schlomm T, Bang H, et al. Expression and prognostic relevance of annexin A3 in prostate cancer. Eur Urol 2008;54:1314-23.

21. Netea-Maier RT, Hunsucker SW, Hoevenaars BM, et al. Discovery and validation of protein abundance differences between follicular thyroid neoplasms. Cancer Res 2008;68:1572-80.

22. Zeng C, Ke Z, Song Y, et al. Annexin A3 is associated with a poor prognosis in breast cancer and participates in the modulation of apoptosis in vitro by affecting the Bcl-2/Bax balance. Exp Mol Pathol 2013;95:23-31.

23. Yan X, Yin J, Yao H, et al. Increased expression of annexin A3 is a mechanism of platinum resistance in ovarian cancer. Cancer Res 2010;70:1616-24.

24. Pan QZ, Pan K, Wang QJ, et al. Annexin A3 as a potential target for immunotherapy of liver cancer stem-like cells. Stem Cells 2015;33:354-66.

25. Wang S, Zhang Z, Qian W, et al. Angiogenesis and vasculogenic mimicry are inhibited by $8-\mathrm{Br}$-cAMP through activation of the cAMP/PKA pathway in colorectal cancer. Onco Targets Ther 2018;11:3765-74. 